\title{
Changes in Energy Expenditure in Preterm Infants During Weaning: A Randomized Comparison of Two Weaning Methods from an Incubator
}

\author{
VALENTIN WEINTRAUB, FRANCIS B. MIMOUNI, AND SHAUL DOLLBERG \\ Department of Neonatology [V.W., F.B.M., SD], Lis Maternity Hospital, Tel Aviv Sourasky Medical Center, Tel Aviv, 64239, Israel; \\ Sackler Faculty of Medicine [F.B.M., SD], Tel Aviv University, Tel Aviv, 64239, Israel
}

\begin{abstract}
We aimed to compare resting energy expenditure (REE) of infants exposed to either one of two weaning methods and to confirm the increase in REE during weaning from incubator. The study was a prospective randomized clinical trial of weaning preterm infants using either of two methods. REE was measured at baseline and $6,23,30$, and $47 \mathrm{~h}$, using indirect calorimetry. At measurement, infants were clinically and thermally stable, asleep, $2 \mathrm{~h}$ after feeding. Forty-two patients were randomized to "open incubator" $(n=23)$ or "warming bassinet" $(n=19)$. The groups did not differ in baseline clinical characteristics. REE increased significantly in both groups within $23 \mathrm{~h}$, and remained stable at 30 and $47 \mathrm{~h}$. At 6 and $23 \mathrm{~h}$, the incubator group had significantly higher increase in REE than the warming bassinet group. By $30 \mathrm{~h}$ and at $47 \mathrm{~h}$ post-weaning, the REE of both groups became similar. In conclusion, REE increases significantly at weaning from incubator. The warming bassinet delays the increase in REE observed when infants are weaned using a turned off incubator. Whether one method is superior to the other in terms of thermic stress cannot be determined from this study. (Pediatr Res 61: 341-344, 2007)
\end{abstract}

$\mathrm{P}_{\mathrm{e}}^{\mathrm{r}}$ reterm very low birth weight infants require a heated environment to survive because of a combination of increased heat losses, and of reduced thermal production (1). When they reach the weight of 1500-2000 g, most preterm infants acquire thermal competency and can survive standard room temperatures (2). The transition from an incubator environment to a room temperature environment (also called weaning, or "cold stress") is usually conducted in a gradual fashion. During that period, we showed in a small pilot study that the REE of the infant increases significantly (3).

In North America, when one infant is considered as capable of weaning, it is usually fully dressed and wrapped in blankets, the incubator portholes are kept open, and the incubator temperature is left to drop. If core temperatures remain stable, the infant is then placed in a regular bassinet. If not, the incubator is turned on again and further attempts of weaning are made several days later. In Israel, as well as in many western European countries, the infant is fully dressed and

Received August 8, 2006; accepted October 19, 2006.

Correspondence: Shaul Dollberg, M.D., Department of Neonatology, Lis Maternity Hospital, Tel Aviv-Sourasky Medical Center, 6 Weizman Street, Tel Aviv, 64239, Israel; e-mail: dolberg@post.tau.ac.il

The study was supported, in part, by a grant from the Chief Scientist of the Israeli Ministry of Health.

DOI: $10.1203 /$ pdr.0b013e318030d1aa wrapped, then placed in an "open air" warming bassinet (which warms up a gel-filled mattress on which the infant lays down) (S. Demarini, M.D., personal communication). If core temperature remains stable, the next step is to turn off the heat of the bassinet; if not, the infant is retuned to the incubator. Additionally, there is the option of a more abrupt weaning: when the infant is deemed ready it is taken out of the incubator and put into an open cot at room temperature.

The aim of this study was to confirm the increase in REE observed in our previous study and to compare the REE of infants exposed to either one of the two above-mentioned methods of weaning. We elected to study a relatively heterogeneous group to obtain, at the time the REE would be measured, a group of infants with a wide range of postnatal age, which would allow one to better determine the role of postnatal age upon REE. We hypothesized that 1) during weaning there is a progressive increase in REE; and 2) the warming bassinet method allows for a more gradual increase in REE than the open incubator method.

\section{METHODS}

Design. We conducted the study at the neonatal intensive care unit of the Tel Aviv Medical Center between September 2000 and August 2003. This study was designed as a prospective clinical trial comparing weaning of preterm infants from a commercial, skin servo-controlled convective incubator set to $36.0^{\circ} \mathrm{C}$ with room temperature using randomization to either a commercial warming bassinet or keeping the infant in its own turned off incubator with opened portholes. The study was not blinded because it was not technically possible to prevent the investigators measuring REE to know the method of weaning. In this study, before weaning, all infants were cared for in a Hill-Rom Air-shield Isolette C2000 (Philadelphia, PA). The warming bassinet used in this study was a Babytherm 8000 IC (Draeger, Luebeck, Germany). In both arms of the randomization, infants were fully dressed in a similar fashion (two layers of cotton shirts and two layers of cotton pants that cover the feet and a woolen hat). All infants were covered with two acrylic blankets. Then, and for the next $23 \mathrm{~h}$, either all portholes were opened, and the heat of the incubator turned off ("incubator group"), or the infant was placed in the warming bassinet ("warming bassinet group"). After $23 \mathrm{~h}$, infants from both groups were placed in a regular bassinet at room temperature (airconditioned to $22-23.5^{\circ} \mathrm{C}$ ). REE was the primary outcome for this study. REE measurements were conducted at baseline ( $1 \mathrm{~h}$ before weaning), at $6 \mathrm{~h}$, at $23 \mathrm{~h}$ (before placement in an open air bassinet), at $30 \mathrm{~h}$, and at $47 \mathrm{~h}$ from baseline).

Patients. Institutional review board permission of the study was granted and written informed parental consent was obtained for each of the participants. We elected to study a relatively heterogeneous group to obtain, at the time the REE would be measured, a group of infants with a wide range of postnatal age, which would allow one to better determine the role of postnatal

Abbreviations: EE, energy expenditure; REE, resting energy expenditure 
age upon REE. By design, we elected to study preterm infants as soon as they were declared healthy, medically stable, and with a good potential to wean from the incubator, i.e. when they had stable vital signs, a core temperature while in the incubator at $\geq 36.5^{\circ} \mathrm{C}$ and $\leq 37.5^{\circ} \mathrm{C}$ for more than $12 \mathrm{~h}$, while being kept at an environmental temperature within the limits of neutral thermal environmental temperature described by Scopes and Ahmed for each given baby (4), and a weight ranging from 1500 to $2100 \mathrm{~g}$. All infants were studied at the time they were able to tolerate full feeds, i.e. $150-180 \mathrm{~mL} / \mathrm{kg} / \mathrm{d}$ (or when they fed ad libitum at the breast or at the bottle, for infants delivered at $>33$ wk gestation). Infants born at a birth weight of 500-2000 g were eligible for the study. Once the infants had reached the eligibility criteria they were recruited and entered into the trial at that time. Excluded from the study were 1) unstable infants by core temperature, blood pressure, or heart rate, or with respiratory instability (e.g. requirement of supplemental oxygen or respiratory support); 2) infants with congenital malformations; 3 ) infants with known maternal thyroid disease or those treated with medications known to affect metabolism, e.g. steroids, methyl-xanthines, beta-blockers, etc., during the past $3 \mathrm{~d}$; 4) infants with brain injury (including grade III or more hemorrhage); 5) infants with bronchopulmonary dysplasia; 6) infants with withdrawal syndrome; 7) infants receiving phototherapy; and 8) infants born small for gestational age (SGA).

Failure to wean from the incubator to an open crib was defined as axillary temperature that dropped below $36^{\circ} \mathrm{C}$ for a period of more than $2 \mathrm{~h}$ at any stage of the weaning process. Infants who failed to wean, were placed into their incubator and were not included in the final analysis. They were all studied in comparable environmental conditions, in that they were cared for in a skin servo-controlled incubator set up to maintain skin temperature at $36^{\circ} \mathrm{C}$ (1), and ambient humidification of $30 \%$. The temperature in the neonatal intensive care unit in which the study was performed is maintained within a range of $22-23.5^{\circ} \mathrm{C}$ by a computerized air conditioning system. Before the study, and according to our feeding protocol (5), each infant received expressed breast milk (150-180 mL/kg weight/d) "fortified" to $102 \mathrm{~kJ} / 100 \mathrm{~mL}$ using of a commercial human milk fortifier (Similac Natural Care, Ross Laboratories, Columbus, $\mathrm{OH}$ ), a combination of fortified breast milk and 102 $\mathrm{kJ} / 100 \mathrm{~mL}$ formula (Similac Special Care, Ross Laboratories), or Similac Special Care alone (per maternal choice). Thus, at the time they were studied, all infants had an energy intake ranging between 502 and $569 \mathrm{~kJ} / \mathrm{Kg} / \mathrm{d}$. Because of the known effect of energy intake upon REE (6), the actual energy intake on the day the infant was studied was calculated, based upon the actual intake in formula-fed infants, and on the assumption of a caloric content of $102 \mathrm{~kJ} / 100 \mathrm{~mL}$ for fortified breast milk $(85 \mathrm{~kJ} / 100 \mathrm{~mL}$ for the breast milk plus the additional $17 \mathrm{~kJ} / 100 \mathrm{~mL}$ of the human milk fortifier). We also calculated the average daily weight gain (or loss) in the last $3 \mathrm{~d}$ that preceded the study in each infant and expressed it in $\mathrm{g} / \mathrm{d}$.

Measurements of REE. REE was measured using a Deltatrac II oxygen consumption analyzer (Datex, Helsinki, Finland). This device is based on indirect calorimetry (7). By measuring oxygen consumption as well as carbon dioxide production, EE can be calculated by knowing the rate at which oxygen is used. This method has been shown to be equivalent to direct measurements (8). This commonly used method allows prolonged measurements while allowing reasonable access to the infant for routine care. All measurements were started $2 \mathrm{~h}$ after feeding while the infants were quiet and asleep. Measurements were stopped during body movements (less than 5\% of the time of measurement) and resumed afterward, for a total measurement time of $1 \mathrm{~h}$. In our hands, the intraindividual coefficient of variation of the measurement is $3 \%$ (6). Hematocrit measured within a week of the study was used since anemia was reported to cause a change in oxygen requirement (9).

We used the results of the Israeli National Thyroid Screening Program to evaluate the thyroid function of all infants. In this program, a few drops of blood are obtained by heel-stick and collected on filter paper at $\mathrm{d} 3$ of life and measured for T4 by RIA.

Statistical methods. Randomization was performed by computergenerated random numbers, using sealed opaque envelopes. The randomization was stratified according to three birth weight groups (500-1000 g, $1001-1500 \mathrm{~g}$, and $1501-2000 \mathrm{~g}$ ), to insure an adequate comparability of the groups, as much as possible. Sample size calculation was based on a $10 \%$ difference between REE in the two methods of weaning with $\alpha$ of 0.05 and power of 0.8. Statistical analysis was performed using Minitab for Windows (Minitab, State College, PA). All baseline and demographic variables were tested for normality and, if distributed in a non-normal manner, nonparametric tests were used. The comparability of the two randomization groups was assessed by $t$ test or Kruskal-Wallis test for continuous variables, and Fisher's exact test for categorical variables. Repeated measures ANOVA was used to compare REE between the two groups while taking into account the time and subjects factors, as well as potential confounders such as birth weight (or gestational age at birth), postnatal age, or dietary intake on the day of
Table 1. Demographic characteristics of the study infants [mean $\pm S D$ or $n(\%)]$

\begin{tabular}{lcc}
\hline & $\begin{array}{c}\text { Turned off incubator } \\
(n=23)\end{array}$ & $\begin{array}{c}\text { Warming } \\
\text { bassinet } \\
(n=19)\end{array}$ \\
\hline Birth weight $(\mathrm{g})$ & $1361 \pm 379$ & $1352 \pm 410$ \\
Gestational age (wk) at birth & $30.6 \pm 2.4$ & $31.5 \pm 3.0$ \\
$\begin{array}{l}\text { Gender (male:female) } \\
\text { Presence of respiratory distress }\end{array}$ & $14: 9$ & $10: 9$ \\
syndrome at birth & $13(57 \%)$ & $7(37 \%)$ \\
Weight at weaning (g) & $1674 \pm 139$ & $1659 \pm 118$ \\
Postnatal age at weaning (d) & $28 \pm 19$ & $28 \pm 21$ \\
Hematocrit at weaning (\%) & $41 \pm 10$ & $43 \pm 13$ \\
Thyroxine concentration (T4) & $7.5 \pm 1.9$ & $9.2 \pm 3.0$ \\
$(\mu \mathrm{g} / \mathrm{dL})$ & & \\
\hline
\end{tabular}

weaning. Results are expressed as $n(\%)$ or mean $\pm \mathrm{SD}$; a $p$ value of $<0.05$ was considered significant.

\section{RESULTS}

We studied a total of 42 patients distributed among the three birth weight subgroups and the two randomized groups. Some of the data reported in this paper overlaps with that of 16 out of the 42 infants of the pilot study previously published (3). Twenty-three of the 42 infants were weaned using the "open incubator" method, while 19 were weaned using the "warming bassinet" method. Table 1 depicts the major clinical and laboratory characteristics of the infants. Briefly, the two groups did not differ in terms of birthweight, gestational age, weight at the time of weaning, and age at the time of weaning. They also had similar hematocrit at the time of weaning, and T4 concentrations at the time of routine screening ( $5 \mathrm{~d}$ of age).

Figure 1 depicts the changes in REE over time in both groups. Resting EE increased significantly over time in both groups within the first $23 \mathrm{~h}$, and then remained stable at 30 and $47 \mathrm{~h}$ Post-weaning. There were no significant differences in REE at baseline between groups of weaning. At 6 and $23 \mathrm{~h}$ post weaning, the incubator group had a significantly higher increase in REE than the warming bassinet group. The average difference between the two groups after the first day of

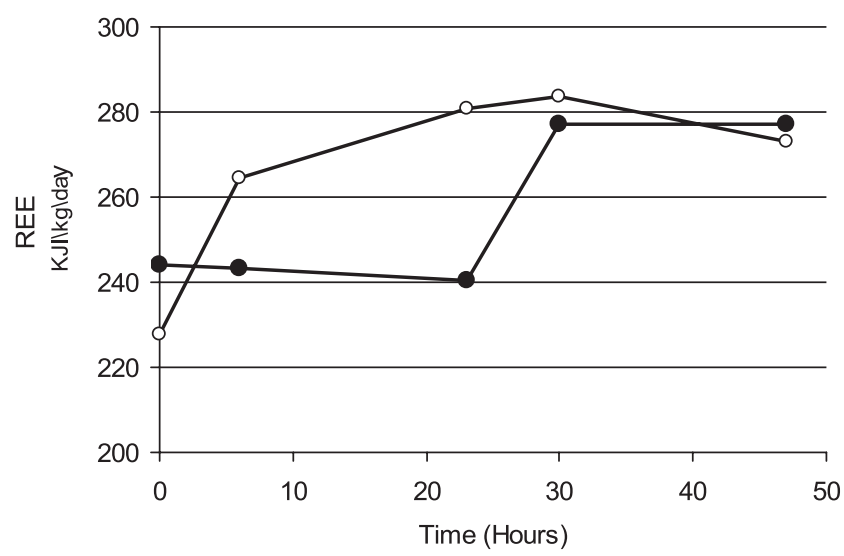

Figure 1. REE during weaning from incubator in preterm infants. In one group infants were weaned by having all portholes opened and the heat of the incubator turned off (incubator group, open circles). In the other group, infants were placed in a warm bassinet (warming bassinet group, closed circles). 
weaning was about $42 \mathrm{~kJ} / \mathrm{kg} / \mathrm{d}$. By $30 \mathrm{~h}$ and at $47 \mathrm{~h}$ postweaning, the REE of both groups became very similar.

In repeated measures ANOVA, we studied the impact of the variables that potentially affect the increase in REE. Sex influenced significantly the rate of increase in REE, in that, although the baseline, pre-weaning REE was similar between sexes, at all data points post weaning girls had a higher increase in REE. Babies born at the highest birth weight category had the lowest baseline REE and the highest increase in REE. Gestational age at birth, and T4 values did not influence significantly the rate of increase in REE.

A comparison of the six infants who failed weaning with the 36 ones that had a successful weaning from the incubator revealed that the following factors were not significantly influential: mode of weaning [ 2 failures/19 infants (10.5\%) in the warming bassinet group versus $4 / 23(17.4 \%)$ in the incubator group, $p=0.67$ by Fisher's exact test]; birth weight, postnatal age, postmenstrual age, and hematocrit. Baseline REE was almost significantly lower $(p=0.06)$ in the failed group $(219 \pm 11 \mathrm{~kJ} / \mathrm{kg} / \mathrm{d})$ than in the successful group (236 \pm $7 \mathrm{~kJ} / \mathrm{kg} / \mathrm{d})$.

Using linear regression analysis, we found that the REE at baseline correlated inversely with birth weight and directly with postnatal age. Pre-weaning REE was not influenced by gestational age, T4 concentrations, or sex.

\section{DISCUSSION}

Our study confirmed our first hypothesis that REE increases during weaning. Although this finding is logical from a theoretical standpoint, our study is the first that aimed to measure REE in a longitudinal manner in preterm infants and confirmed the increase of REE at the time of weaning. We speculate that the calories spent in increasing REE become unavailable for growth and are compensated later on either by an increase in caloric intake and/or a decrease in heat losses.

While there were no significant differences in REE at baseline between groups of weaning, at 6 and $23 \mathrm{~h}$ post weaning, the incubator group had a significantly higher increase in REE than the warming bassinet group. Thus, it appears that, contrary to our hypothesis, the warming bassinet provides a less gradual weaning and only delays the mandatory increase in REE that occurs at weaning. Although there were no significant differences in failure rates between the two methods $(10.5 \%$ in the "warming bassinet" group versus $17.4 \%$ in the "incubator group," $p=0.67$ ), this study was not sufficiently powered to guarantee that a type 2 error did not occur. Indeed, if we assume that the difference between $10.5 \%$ and $17.4 \%$ is a true one, we would need a sample size of 395 patients in each group to demonstrate it, a task nearly impossible to achieve in a single center, due to time limitations. Thus, cost-effectiveness calculations based upon success or failures were not possible.

A comparison of the 6 infants who failed weaning with the 36 that had a successful weaning from the incubator revealed that, birthweight, postnatal age, postmenstrual age, and hematocrit were similar between the two groups.
The only one variable that approached statistical significance $(p=0.06)$ was baseline REE (higher in the successful group than in the failed group). We speculate that higher baseline REE (which was found in the babies born at lower gestational ages) confers a homeothermic advantage.

We found that, just before weaning, infant birth weight correlated significantly and inversely with baseline REE. Because, by our clinical protocol, infants needed to reach a weight of at least $1600 \mathrm{~g}$ at the time of weaning, it means that the smallest infants at birth had, when they reached the "weaning weight," the highest REE. Thus, we speculate that there is a postnatal maturation of thermoregulation that may occur faster than that the intrauterine maturation. Similarly, postnatal age correlated directly with baseline REE, just before weaning. This could be due to the fact that a relatively "young" postnatal age at the time the infant reaches the weight of weaning (at least 1600-1700 g) indicates that the infant was born at a relatively advanced gestational age, while an "older" postnatal age at the time the infant reaches the weight of weaning indicates that the infant was born at a relatively low gestational age. However, gestational age at birth per se did not correlate with baseline REE, in contrast with birthweight. Thus, it may appear that weight (i.e., a component of body composition), may be a more important parameter in the control of thermoregulation of the preterm infant than gestational age. Other demographic parameters such as sex did not correlate with baseline REE.

In repeated measures ANOVA, we found that sex influenced significantly the rate of increase in REE, in that, although the baseline, pre-weaning REE was similar between sexes, at all data points post-weaning girls had a higher increase in REE. A careful review of the literature did not reveal any such finding, with the exception of the work by Glass et al. (10) that found in term infants an "interesting relationship between sex and metabolic rate ... where as a group (similar to our study) female infants exhibited higher metabolic rates under subthermoneutral conditions than the male infants." Neither Glass and colleagues, nor we, can explain this sexual dimorphism, which obviously requires additional studies.

Birth weight category influenced significantly the rate of increase in REE, in that babies born at the highest birthweight category had the lowest baseline REE and the highest increase in REE. Once again, we speculate that, at the time weaning weight was reached, the heaviest infants at birth were in effect the youngest (in term of postnatal age).

In summary, REE increases significantly at the time an infant is weaned from the incubator. The warming bassinet method of weaning appears to delay the mandatory increase in REE that is observed when infants are weaned using a turned off incubator. Whether one method appears to be superior to the other in terms of thermic stress or in terms of failure to wean rates cannot be determined from this study.

\section{REFERENCES}

\footnotetext{
1. Sedin G 2006 The thermal environment of the newborn infant. In: Martin RJ, Fanaroff AA, Walsh MC (eds) 2006 Neonatal Perinatal Medicine. Elsevier Mosby, Philadelphia, pp 585-597
} 
2. New K, Flenady V, Davies MW 2004 Transfer of preterm infants from incubator to open cot at lower versus higher body weight. Cochrane Database Syst Rev 2:CD004214.

3. Dollberg S, Mimouni FB, Weintraub V 2004 Energy expenditure in infants weaned from a convective incubator. Am J Perinatol 21:253-256

4. Scopes JW, Ahmed I 1966 Indirect assessment of oxygen requirements in newborn babies by monitoring deep body temperature. Arch Dis Child 41:25-33

5. Dollberg S, Kvint J, Mazkereth R, Mimouni FB 2000 Feeding tolerance in preterm infants: randomized trial of bolus and continuous feeding. J Am Coll Nutr 19:797800

6. Lubetzky R, Vaisman N, Mimouni FB, Dollberg S 2003 Energy expenditure in human milk versus formula fed preterm infants. J Pediatr 143:750-753
7. Thureen PJ, Phillips RE, DeMarie MP, Hoffenberg A, Bronstein MN, Spedale SB, Hay Jr WW 1997 Technical and methodologic considerations for performance of indirect calorimetry in ventilated and nonventilated preterm infants. Crit Care Med 25:171-180.

8. Jequier E, Felber J 1987 Indirect calorimetry. Baillieres Clin Endocrinol Metab 1:911-935

9. Weiskopf RB, Viele MK, Feiner J, Kelley S, Lieberman J, Noorani M, Leung JM, Fisher DM, Murray WR, Toy P, Moore MA 1998 Human cardiovascular and metabolic response to acute, severe isovolemic anemia. JAMA 279:217-221

10. Glass L, Silverman WA, Sinclair JC 1969 Relationship of thermal environment and caloric intake to growth and resting metabolism in the late neonatal period. Biol Neonat 14:324-340 